Research Article

\title{
Traffic Allocation Mode of PPP Highway Project: A Risk Management Approach
}

\author{
Jie Li (iD, Peng Mao, Zhaohua Dai, and Jing Zhang \\ School of Civil Engineering, Nanjing Forestry University, Nanjing, Jiangsu 210037, China \\ Correspondence should be addressed to Jie Li; nldlijie@163.com
}

Received 20 April 2018; Revised 8 July 2018; Accepted 5 August 2018; Published 24 September 2018

Academic Editor: Bill Zhao

Copyright ( $\odot 2018$ Jie Li et al. This is an open access article distributed under the Creative Commons Attribution License, which permits unrestricted use, distribution, and reproduction in any medium, provided the original work is properly cited.

\begin{abstract}
Highway projects are the favorites of public-private partnership (PPP) investors because of their stable cash flow. However, there are high uncertainties in terms of traffic volume, resulting in unpredictable revenues, which has drawn major concern of PPP investors. For a road in a network, the traffic volume is determined by the traffic allocation rate, which is affected not only by the total traffic volume in the region but also by other traffic risk factors, such as travel time, toll rates, and travelling comfort. The conventional traffic allocation forecasting technique predominantly depends on the travel time, overlooking other risk factors. Consequently, traffic allocation forecasting is usually inaccurate. To improve the accuracy of traffic allocation forecasting in PPP road projects, this paper proposes to consider the effect of traffic risks together with traffic time by using the mean utility. Multinomial logit (MNL) model based on mean utility is used to predict the traffic allocation rate. To validate the proposed model, the system dynamic (SD) modeling is established to forecast the traffic volume of a case highway using the proposed traffic allocation forecasting model. The simulated result shows that the simulated traffic volume of past years from the proposed model is highly consistent with the actual one, evidencing that the proposed model can greatly improve the accuracy of the traffic forecasting.
\end{abstract}

\section{Introduction}

PPP investors prefer highway projects because of their stable cash flow and relatively low level of competition. The early highways, such as Guangshen Expressway in China, Bangkok Expressway in Thailand, and the North-South Expressway in Malaysia, were all built via a built operation transfer (BOT)/public-private partnership (PPP) scheme. However, many early BOT/PPP projects including highway projects in China were stopped by the central government in 1999 due to unfair contract conditions [1]. To accelerate the development of new highways and to facilitate the national expressway network in China, the Traffic Financing and Investment Company has been established to finance highway projects through toll collection. Under this scheme, highway development has been greatly accelerated. By 2015, the highway mileage has reached $120000 \mathrm{~km}$ [2]. However, because the actual traffic volume of some highways is less than the predicted value [3] and the construction speed is high, the debt of local governments has dramatically increased. According to the Ministry of Transport of the People's Republic of China, the gap between the debt and the revenue reached RMB 318.73 billion yuan in 2015 [4]. To relieve pressure of the local governments, the State Council released "Guidelines for Improving the Management of Local Government Debt." The investment from enterprises, both state owned and private, is then reencouraged to invest into highway construction using a PPP scheme under the provision of concessions. Construction is a risky business, especially in infrastructure projects $[5,6]$. One of the important reasons of early unsuccessful BOT/PPP projects is the negligence of the demand risks. Therefore, the traffic volume is always will be the most critical risk to the return of investment.

Some studies have investigated the traffic volume risk from the perspective of risk management. Ashuri et al. [7] pointed out that uncertainty about future traffic demands is one of the most significant risks during the operation phase 
of BOT projects. They applied the real options theory to determine the minimum revenue guarantee (MRG) option price in BOT projects. Iyer and Sagheer [8] adopted the model concession agreement (MCA), a standardized risk allocation framework, to treat risks for BOT highway projects in India. If the actual traffic volume deviates from the projected traffic, the MCA suggests varying the length of the concession period by a preagreed formula to mitigate the traffic demand risk. To avoid gaining excess profit or being unable to get the expected profit in the situation where traffic demand deviates from the expectation, Song et al. [9] discussed the single adjustment and linkage adjustment on toll rates and concession period. These studies predominantly focused on the quantitative impact analysis of traffic risk on other factors. There is little literature discussing the impact of other factors on traffic volume risk, although they are actually interactive.

Traffic volume risk has been discussed in the context of Traffic Engineering. Apronti et al. [10] estimated traffic volume on Wyoming low-volume roads using linear and logistic regression methods. Xiang [11] proposed a road impedance model based on the traditional Green shields linear model of traffic wave theory. Soliño et al. [12] measured the uncertainty of traffic volume on motorway concessions by using a time-series model. Song et al. [13] improved the dynamic road impedance function based on traffic wave theory. Liu and Chen [14] deduced the relationship between link flow and travel time in congested and noncongested conditions based on the Edie model. However, these studies mainly discuss the influence of travel time on traffic volume, ignoring other risks, such as users' willingness to pay, high toll rates, and long concession period of PPP highways projects.

To analyze the impact of other risk factors on traffic volume, risk assessment is necessary. According to Risk Management: Principles and Guidelines (AS/NZS ISO31000, p. 18) [15], "Risk analysis can be qualitative, semiquantitative, or quantitative, or a combination of these, depending on the circumstances." Although statistical analysis is ideal for quantitative assessment, most risks in PPP projects are difficult to quantify because the underpinning information is usually unavailable or insufficient. Therefore, qualitative risk assessment has been mainly conducted. In the early stage, Wang et al. [16] evaluated risks by using the 5-scale method. Kuchma [17] put forward a fuzzy way of measuring the criticality of project activities. Recently, Xu et al. [18] set up a fuzzy synthetic model which could be directly used for PPP highway projects. Li and Zou [19] developed a fuzzy AHP-based risk assessment methodology for PPP projects. Ning and Zhao [20] established a risk assessment procedure through expert interviews and two-round Delphi. Wang et al. [21] applied the theory of real option and the theory of the bargaining game to assign the option value between two parties and to establish the distribution principles of PPP projects in terms of excess return. $\mathrm{Wu}$ et al. [22] assessed the risks in PPP straw-based power generation projects using the fuzzy synthetic evaluation method. However, Walker and Smith [23] pointed out that, by studying the magnitude of the possible impact that may be caused by contingent factors, the parties can better allocate the risks through contract clauses, procurement of insurance, or other risk response measures. $\mathrm{Ng}$ and Loosemore [26] also pointed out "there is considerable evidence to suggest that risk transfer is often handled poorly between parties to many PPP projects. For a host of reasons, parties to concession projects take risks which they are not clear of, or they are not able to cope with, or they do not have the appetite for and cannot charge for." Thus, a carefully prepared quantitative risk analysis is necessary to produce more positive and rational risk-taking attitude if the risktaking parties know where they stand.

To improve the accuracy of forecasting the traffic volume, the road allocation rate is the key. This paper proposes to predict the traffic volume by considering the effect of risks on the traffic allocation rate. Firstly, the recent PPP highway projects are analyzed to identify the main risks affecting the traffic volume. The effect of the traffic risks together with traffic time is considered by using the model of mean utility of users. Then, the MNL model based on mean utility of users is proposed to compute the traffic allocation rate. To determine the effect of risks on traffic allocation, they are quantitatively measured using multiple linear regression analysis with SPSS based on the questionnaire. Finally, system dynamic (SD) models of the proposed traffic allocation model were established to validate the model by comparing the simulated traffic volume of past years of a case highway with the actual volume.

\section{Case Analysis of PPP Highway Projects}

For discussion, the PPP highway projects cover the roads and bridges in this paper. Investors gain returns of investment (ROI) by collecting tolls. Seven BOT/PPP highway projects were selected to analyze the related risks (Table 1). These projects spread across China, namely, cases $1,3,4$, and 5 in the east part, case 2 in the south part, case 6 in the north part, and case 7 in the west part. They are built at different stages of PPP development in China and invested by various sources. In China, BOT/PPP projects were invested by investors from abroad and Hong Kong before 1999 [1]. Cases 2, 4, 5, and 6 were executed before 1999 and invested by Hong Kong investors. After 1999, BOT/PPP projects were invested by mainland investors (because the fixed return condition to investors was not allowed in concession contracts and loses the attraction of foreign and Hong Kong investors by then); cases 1, 3, and 7 were after 1999. Although the location, execution time, and investors of these projects are different, they all encountered common problems. Some stopped the contract at the compensated return much lower than the promised fixed return rate in the concession contracts. Some are in operation, but opposed by users because of the traffic congestion and/or high toll rates. The qualitative risk analysis (Table 1) shows that traffic volume risk is the most common risk, appearing in five projects in two ways: insufficient traffic volume and underestimated traffic volume. Other risks include high toll rates, long toll collecting period, public opposition, traffic congestion, poor 
TABLE 1: The qualitative risk analysis of the PPP highway projects.

\begin{tabular}{|c|c|c|c|}
\hline Number & Project name & Case description & Risk analysis \\
\hline 1 & $\begin{array}{c}\text { Hangzhou Bay } \\
\text { Sea-Crossing Bridge }\end{array}$ & $\begin{array}{l}\text { The projected traffic volume was } 14.152 \text { million vehicles in } 2008 \text {. But the } \\
\text { actual traffic volume was only } 11.124 \text { million in } 2010 \text { and } 12.524 \text { million in } \\
\text { 2012. The actual traffic volume varied significantly from the projected value } \\
\text { in the feasibility study report in } 2003 \text {. The toll as the only source of income } \\
\text { was } 643 \text { million yuan in 2013, a return on investment of } 4 \% \text {. It was far less } \\
\text { than } 12.8 \% \text { as projected. In July } 2013 \text {, the second crossing-sea bridge } \\
\text { Jiashao Bridge over Hangzhou Bay was open to the public, decreasing the } \\
\text { revenue further. }\end{array}$ & $\begin{array}{c}\text { Insufficient traffic } \\
\text { Competitive road diversion }\end{array}$ \\
\hline 2 & $\begin{array}{l}\text { Guangshen } \\
\text { Highway }\end{array}$ & $\begin{array}{l}\text { The traffic on Guangzhou-Shenzhen Expressway is always heavy and } \\
\text { congested, causing traffic accidents. The revenue has exceeded greatly than } \\
\text { predicted since its open to the public. The high return on investment had } \\
\text { drawn public concern where cutting the charge level has been strongly } \\
\text { advocated. Poor road conditions, serious congestion, and high tolls had } \\
\text { become its major criticisms. }\end{array}$ & $\begin{array}{l}\text { Underestimated traffic } \\
\text { Poor road conditions } \\
\text { Traffic congestion } \\
\text { High toll rate } \\
\text { Public opposition }\end{array}$ \\
\hline
\end{tabular}

Nanjing Third Yangtze River Bridge was designed to attract the traffic from Anhui Province to Jiangsu Province. The traffic to and from Anhui is for free on Nanjing First Yangtze River Bridge. In 2007, there were only 15,000 vehicles per day while the traffic of Nanjing First Yangtze River Bridge was
Nanjing Third Bridge Yangtze River 60,000 vehicles. With the continuous improvement of the surrounding road network, more traffic would be diverted. The future of the Third Yangtze River Bridge is not optimistic. Therefore, the toll rates of the Third Bridge were cut down to attract vehicles. However, drivers still preferred going through crowded but free Yangtze River Bridge. As a result, the toll collecting period was officially extended from 25 years to 30 years. The public strongly opposed the period change and questioned constantly.

Before the construction of the Citong Bridge, there is the Quanzhou Bridge over Jinjiang. Before 1997, the revenue of Quanzhou Bridge was handed to the provincial treasury. So Quanzhou municipal government strongly supported the construction of the Citong Bridge. However, in 1997, the provincial government transferred the operation of Quanzhou Bridge to the Quanzhou municipal government back. The original annual income of Quanzhou Bridge was 50 million. After the completion of the Citong Bridge, the traffic of Quanzhou Bridge suffered steep losses. Its annual income plunged to 30 million. The Citong Bridge and the Quanzhou Bridge became direct competitive bridges. Thus, the existing of Citong Bridge had threated the benefits of Quanzhou Bridge.

Fuzhou municipal government has explicitly guaranteed that all vehicles from the south gate of Fuzhou would go through the Xinyuan Fourth Minjiang River Bridge for 9 years since it was opened to public in 1997, with an annual net ROI of 18\%. However, in May 2004, Fuzhou second ring road opened whose access was less than two hundred meters from Baihuting toll stations. Since then, many vehicles bypassed the toll stations to go through the free second ring road, resulting in a sharp decline of the revenue of the fourth bridge. Given no further negotiations were approved, the private sector applied for arbitration.

$5 \quad$ Xinyuan Fourth Bridge

Highway

Hebei Fude

The Fude Highway was located on the traffic arteries. Its actual traffic growth was far beyond the predictions. In the 8th year, the total investment had been recovered. In addition to operation cost and tax, the operation of the remaining decade is very profitable.

There are 4 bridges on Wei River in Xianyang. No. 2 and no. 3 were built under the BOT scheme. The average daily traffic in Xianyang City was

No. 2 and no. 3 100,000 vehicles. Many drivers chose no. 1 Xianyang Bridge as it is free. It caused high traffic pressure and congestion in the city of Xianyang. The public has been requesting the cancellation of tolls at no. 2 and no. 3 bridges to ease the congestion. On May 1, 2011, the municipal government decided to buy back the operation of two bridges. This caused 750 million loss for the investors. Bridge
Insufficient traffic Competitive road diversion Lack of government credit Incorrect prediction of traffic volume

Insufficient traffic

Fixed returns

Competitive road diversion Public opposition Lack of government credit

Underestimated traffic volume

Long toll period

Public opposition

High toll rate 
road conditions, competitive road diversion, and lack of government credit. Most of these risks are closely related to traffic volume except the lack of government credit. It should also be noted that although competitive road diversion may result in insufficient traffic, it will not be considered in this paper because it is out of control of project mangers and may be considered in further study.

The risks under consideration can be divided to different classifications. High toll rates, long toll collecting period, and public opposition decrease users' willingness to pay. Traffic congestion and road conditions affect actual travel time and comfort level. When the congestion of a road is serious and road conditions deteriorate, travel time is extended, and the comfort level goes low. Thus, we divided the risks to three categories: travel time, willingness to pay, and comfort level (Table 2). It should be noted that though willingness to pay and comfort level have the same risk factors, they are different effects both caused by the same two factors. Thus, they were treated as different risk categories' in this paper. In traditional traffic forecasting theories, travel time is the determinant to decide the traffic allocation rate. This paper improves the forecasting method of traffic allocation by considering not only travel time but also users' willingness to pay and comfort level (Table 2).

\section{Research Methodology}

In traditional traffic allocation theories, the road impedance which refers to the sum of travel time and intersection delay is the most important key parameter. It directly determines the road choice and the traffic allocation. The most typical road impedance functions are Bureau of Public Roads (BPR) function, logit delay function, Akcelik delay function, and $\mathrm{EMM} / 2$ tapered delay function [27]. However, they only consider the time-related parameters and overlook the social and socioeconomic factors such as users' willingness to pay and comfort level of a road. As a result, the traffic allocation rate cannot be forecasted accurately based on these functions.

To predict the traffic volume more accurately, flexible demand forecasting methods have consequently been sought, particularly those capable of incorporating the behavioral forces linking individual transportation decisions and the relationships between individual travel choices and aggregate flows. The individual travel decision is determined by travel time, user's willingness to pay, comfort level, trip purpose, etc. Therefore, the route choice of users is not only based on travel time but also on socioeconomic factors.

In the model of consumer behavior in traffic area, consumer behavior is elaborated to focus on the relationship between consumer behavior and transportation. The traffic consumer is assumed to have a utility function bearing both consumption and transportation attributes. The individual's decision on route is affected by the attributes of transport modes, such as travel time, but also by usual budget constraint, the willingness to pay, etc.

A disaggregate choice model is defined by specifying a probability distribution for some unobserved variables (such as willingness to pay), given the values of observed variables (such as travel time and comfort level) in a homogeneous
TABLE 2: The risks related to traffic allocation rate.

\begin{tabular}{lccc}
\hline $\begin{array}{l}\text { Categories } \\
\text { of risks }\end{array}$ & Travel time & $\begin{array}{c}\text { Willingness } \\
\text { to pay }\end{array}$ & Comfort Level \\
\hline $\begin{array}{l}\text { Risk } \\
\text { factors }\end{array}$ & $\begin{array}{c}\text { Traffic } \\
\text { congestion and } \\
\text { poor road } \\
\text { conditions }\end{array}$ & $\begin{array}{c}\text { High toll rates, } \\
\text { long toll period, } \\
\text { and public } \\
\text { opposition }\end{array}$ & $\begin{array}{c}\text { Traffic } \\
\text { congestion and } \\
\text { poor road } \\
\text { conditions }\end{array}$ \\
\hline
\end{tabular}

market segment. This probability distribution determines the choice probabilities and the proportions of the group with maximum utility for each alternative.

The multinomial logit (MNL) model of choice probabilities, viewed as a functional form for alternative (mode) not necessarily a behavioral relationship, has been widely used in transportation planning [25]. It can be derived from the theory of individual choice behavior by assuming that individual utility deviates from mean utility. Mean utility is defined to be the average of the utilities of all individuals in a homogeneous market segment and is viewed statistically independent for different alternatives.

The components of the utility function are consistent with the risks influencing the traffic volume, including consumption and transportation attributes. Thus, the MNL mode is chosen to compute the traffic allocation rate in this research.

3.1. Mean Utility of Users of PPP Projects. McFadden et al. [24] created the average utility formula (1) which can more realistically reflect the aggregated effect on users' choice of road:

$$
V_{i}=-b_{T} \cdot T_{i}-b_{C} \cdot C_{i}+b_{A} \cdot A_{i}
$$

$V_{i}$ is the mean utility of the road $i ; T_{i}$ is the travel time of the road $i ; C_{i}$ is the travel cost of the road $i ; A_{i}$ is the comfort level of the road $i$; and $b_{T}, b_{C}$, and $b_{A}$ are undetermined parameters, on behalf of the marginal utility of each variable.

In formula (1), the mean utility refers to the accumulated psychological experience of public after undergoing a series of favorable and unfavorable factors during use. It is a measure of the satisfaction to the convenience requirements, consisting of travel time, travel cost, and convenience. As the time and cost impede users' convenience experience, they are negative variables in formula (1). In addition, the undetermined parameters only represent the marginal utility of each variable.

As the car traffic increases continuously, it has become the main source of traffic volume. Therefore, this paper studies the mean utility of the road for cars. In addition, the road is divided by toll stations, and the travel time is far beyond the delay at the toll stations. Therefore, the delay at toll stations is not taken into consideration in travel time in this study.

3.2. The Improved Comprehensive Mean Utility of Users of PPP Highway Projects. It can be observed that there is a oneto-one correspondence between the parameters $T_{i}, C_{i}$, and $A_{i}$ in formula (1) and risk categories (travel time, willingness to pay, and comfort level) in Table 2. Therefore, risk coefficients were introduced to quantify relevant risks based on 
the mean utility formula and the actual traffic situation. Consequently, the comprehensive mean utility function was constructed to predict actual practices.

\subsubsection{Travel Time Risk Coefficient: The Time Cost Coefficient} $a_{i 1}$. Road traffic time = highway length/average speed; average speed is calculated with speed-flow general model under any traffic load (formula (2)) [27]:

$$
\left.\begin{array}{l}
U=\frac{\alpha_{1} \cdot U_{s}}{1+(V / C)^{\beta}} \\
\beta=\alpha_{2}+\alpha_{3}(V / C)^{3}
\end{array}\right\},
$$

$U$ is the average speed under the corresponding traffic load $(\mathrm{km} / \mathrm{h}) ; U_{s}$ is the design speed of the corresponding road level $(\mathrm{km} / \mathrm{h}) ; V$ is the traffic volume; $C$ is the highway capacity; $V / C$ is the traffic load of the corresponding road level; $\alpha_{1}, \alpha_{2}$, and $\alpha_{3}$ are regression parameters; for highway, $\alpha_{1}=0.93, \alpha_{2}=1.89$, and $\alpha_{3}=4.86$ [23].

The traffic time is objective and can be calculated by formula (2). It mainly depends on factors such as the design speed, traffic volume, and road traffic capacity. In real life, however, users' satisfaction to the road conditions will change the length of the actual time which we call it psychological time. In other words, psychological time is a mixture of the objective time and the satisfaction of users. The time cost coefficient $a_{i 1}$ was introduced into the model to quantify the influence of serious congestion and poor road conditions upon psychological time cost. It is the ratio of psychological time and the objective travel time. The psychological time would be greater than the actual time in the event of road construction, insufficient road maintenance, and traffic growth. The value of the coefficient will increase in the future.

\subsubsection{Travel Cost Risk Coefficients: Charging Impedance} Coefficient $a_{i 2}$ and Fuel Consumption Coefficient $a_{i 3}$. This paper introduced charging impedance coefficient $a_{i 2}$ and fuel consumption coefficient $a_{i 3}$ to analyze the travel cost.

(1) Charging Impedance Coefficient $a_{i 2}$. The actual tolls of the PPP highway are determined by toll rates and road length. According to the case analysis in Table 1, high tolls and long charging period will draw public opposition. This model introduced the charging impedance coefficient $a_{i 2}$ to quantify the users' willingness to pay. It is the ratio of psychological cost and actual cost. Initially, users cannot adjust to the charging system. Thus, the public will strongly oppose to it and the coefficient value is very high. As the users gradually accept the charging system, the coefficient will reduce gradually. However, the coefficient would increase again if experiencing driving comfort reduction and social and economic disruption. In addition, economic risk factors such as high tolls and long toll collecting period are closely related to the users' ability to pay. Thus, the coefficient also depends on the users' income level. Therefore, the influential factors of charging impedance coefficient are income level, years of use, road condition, and congestion condition.

(2) Fuel Consumption Coefficient $a_{i 3}$. This paper conducted regression simulation of 93\# gasoline price over 10 years. The initial value of gasoline price is set at 1.527 yuan $/ \mathrm{L}$, and price inflation is 0.3487 in the simulation. As the road condition and other factors affect the actual fuel consumption, fuel consumption coefficient $a_{i 3}$ was introduced into this model to more truly reflect the car's fuel consumption, which is the ratio of actual fuel consumption and objective fuel consumption.

3.2.3. Comfort Coefficient $\gamma_{i}$. This paper introduced the comfort coefficient $\gamma_{i}$ to quantify the comfort level perceived by the users. The comfort level also directly affects the psychological travel time. When the comfort level is lower, the travel time feels longer to the users. On the contrary, when the traffic is unobstructed and the road condition is good, the travel time feels shorter, and the comfort level and the coefficient value are higher.

3.2.4. Time Value of Cars $v_{t}$. Time value of cars is defined as the monetary value of the opportunity cost of the time which users consumed on the trip. The travel cost can be converted into generalized travel time via time value of cars. According to literature, the time value of private car drivers should be between 27.82 and 29.17 yuan/hour $[28,29]$. Considering the inflation, the lack of historical data and many other factors, this paper set the average car time value as 22 yuan/hour.

Compared to formula (1), this paper combined the travel time with the comfort coefficient to doubly strengthen the users' consumption psychology. The psychological travel time is represented by the product of the ratio of the computed travel time $t_{i}$ and comfort coefficient $\gamma_{i}$ and time cost coefficient $a_{i 1}$. Similarly, the travel cost is divided into two parts of the tolls and fuel consumption. The public willingness to pay and the actual fuel consumption are represented by the charging impedance coefficient $a_{i 2}$ and fuel consumption coefficient $a_{i 3}$. To unify the measuring units, the time value of cars $v_{t}$ was introduced to convert the travel cost into generalized travel time. The mean utility of PPP highways is represented by psychological travel time and the converted generalized travel time by using the following equation:

$$
M_{i}=a_{i 1} \cdot \frac{t_{i}}{\gamma_{i}}+\left(a_{i 2} \cdot r_{i}+a_{i 3} \cdot p_{e}\right) \cdot \frac{l_{i}}{v_{t}},
$$

$a_{i 1}$ is the time cost coefficient of the road $i, t_{i}$ is the travel time of the road $i, \gamma_{i}$ is the comfort coefficient of the road $i, a_{i 2}$ is the charging impedance coefficient of the $\operatorname{road} i, r_{i}$ is the toll rate, $a_{i 3}$ is the fuel consumption coefficient of the road $i, p_{e}$ is the price of petrol, $l_{i}$ is the length of the road $i$, and $v_{t}$ is the time value of cars.

3.3. The Traffic Allocation Model. The MNL model of choice probabilities based on mean utility of users is used to 
calculate the simulated traffic allocation rate using the following equation:

$$
\left\{\begin{array}{l}
P_{i}=\exp \frac{\left(-\sigma M_{i} / M\right)}{\sum_{k} \exp \left(-\sigma M_{k} / M\right)}, \\
M_{i}=\frac{a_{i 1} t_{i}}{\gamma_{i}}+\left(a_{i 2} r_{i}+a_{i 3} p_{e}\right) \frac{l_{i}}{v_{t}}
\end{array}\right.
$$

$P_{i}$ is the probability of users selecting road i, $M_{i}$ is the mean utility of the road i, $M$ is the average of mean utility of $\mathrm{k}$ roads, and $\sigma$ is the distribution parameter, and $\sigma=3.00$ [23].

\section{The Regression Equations of Main Risk Coefficients}

4.1. Questionnaire Survey. This paper selects the multivariate linear regression method to quantify the risk factors in formula (3). The factors affecting those risks are surveyed using a questionnaire. The questionnaire consists of two parts: the demographic information of respondents and main questions. Demographic information covers gender, driving experience, and monthly income. Main questions are related to psychological time, willingness to pay, and comfort. Respondents are required to answer the questions based on their feelings of overall highway driving experiences. The target respondents were car drivers. In total, 38 questionnaires were sent out, and 37 valid questionnaires were received with a response rate of $95 \%$. Over $70 \%$ of respondents are male, and about $75 \%$ of respondents have a driving experience of more than five years. The number of required samples for the multiple linear regression method should be 3 to 10 times more than the influencing factors. As reported in the previous section, there are 4 influence factors in this study: road condition, congestion condition, income level, and years of driving. A collection of 37 effective responses make it qualified for the regression analysis.

4.2. Multiple Linear Regression Analysis. In this study, the time cost coefficient, charging impedance coefficient, and comfort coefficient were included in the regression analysis. The independent variables and dependent variables of multiple linear regression are shown in Table 3. The scoring of the variables is shown in Table 4. After organizing the survey data, regression analysis was conducted via SPSS. The results are shown in Table 5 and 7.

As shown in Table $5, R^{2}$ values are high, 0.877, 0.867, and 0.963 for three coefficients, respectively, which indicates a good fit of the regression model. Table 6 shows that the probability $P$ values are all less than the significance level of 0.05 , indicating a strong sign of the significant linear relationship between independent variables and dependent variables. Table 7 shows the values of constant terms and the partial correlation coefficients of independent variables of the regression model. Their probability $P$ values are also less than the significance level of 0.05 . The regression equation of each risk factor could be achieved (formula (5)). The risk coefficient values can be determined based on formula (5).

In the practical application, each independent variable value should be within the value range (i.e., minimum and maximum values) in Table 4 . If the values of road condition, congestion condition, and income levels are all 5 and the value of years of use is 10, the values of the time cost coefficient and the charging impedance coefficient will be 0.35 and 0.32 , respectively, which are minimum values. The comfort coefficient value is 1.68 which is the maximum value. When the value of road condition, congestion condition, income levels, and years of use are all 1, the values of the time cost coefficient and the charging impedance coefficient are 1.72 and 1.68, respectively, which are maximum values. The comfort coefficient value is 0.28 which is the minimum value. Therefore, the value range of the time cost coefficient is $(0.35,1.72)$. When the time-cost coefficient value is 1 , the actual travel time is consistent with the psychological feeling time. When the actual time is gradually greater than the psychological time, the value of the time cost coefficient will be gradually greater than 1 . On the contrary, it might be gradually less than 1. The value range of charging impedance coefficient is $(0.32$, 1.68). When the charging impedance coefficient value is 1 , the users can just accept the charging system. The lower the users' willingness to pay is, the greater the charging impedance coefficient value is. On the contrary, it may become smaller gradually. The value range of the comfort coefficient is $(0.28$, 1.68). The higher the comfort level is, the higher the coefficient value is. On the contrary, it may become lower gradually:

$$
\left\{\begin{array}{l}
a_{i 1}=2.059-0.173 \times d_{1}-0.169 \times d_{2}, \\
a_{i 2}=1.955-0.109 \times d_{1}-0.065 \times d_{2}-0.056 \times s_{1}-0.049 \times s_{2}, \\
\gamma_{i}=0.171 \times d_{1}+0.180 \times d_{2}-0.076,
\end{array}\right.
$$

$a_{i 1}$ is the time cost coefficient, $a_{i 2}$ is the charging impedance coefficient, $\gamma_{i}$ is the comfort coefficient, $d_{1}$ is the road condition value, $d_{2}$ is the congestion condition value, $s_{1}$ is the income level, and $s_{2}$ denotes the years of use.

\section{Case Study: System Dynamics Model Simulation Analysis}

5.1. Background. The highway network selected in this paper includes four highways: Xicheng highway, ShanghaiNanjing highway, Changzhou-Hefei highway, and Nantong-Wuxi highway which form the square network structure (Figure 1). Xicheng highway was opened to public in 1999. It has six lanes in both directions. The length of the selected section is about $24 \mathrm{~km}$. Shanghai-Nanjing highway was opened to travel in 1996. It has eight lanes in both directions after reconstruction. The length of the selected section is about $25 \mathrm{~km}$. Changzhou-Hefei highway was opened to travel in 2004. It has four lanes in both directions. The length of the selected section is about $25 \mathrm{~km}$. NantongWuxi highway was opened to travel in 2010. It has six lanes in both directions. The length of the selected section is about $28 \mathrm{~km}$. They were all invested by the Traffic Financing and Investment Company of Govenment and built under the 
TABLE 3: Independent variables and dependent variables of multiple linear regression.

\begin{tabular}{|c|c|}
\hline The dependent variables & The independent variables \\
\hline Time cost coefficient & Road condition and congestion condition \\
\hline Charging impedance coefficient & $\begin{array}{c}\text { Road condition, congestion condition, income level, } \\
\text { and years of use }\end{array}$ \\
\hline Comfort coefficient & Road condition and congestion condition \\
\hline
\end{tabular}

TABLE 4: Scoring of variables.

\begin{tabular}{|c|c|c|}
\hline Number & The variable name & Definition \\
\hline 1 & Road condition & $\begin{array}{c}\text { 5: very good; 4: good; 3: neutral; } 2: \text { poorer; } 1 \text { : very } \\
\text { poor }\end{array}$ \\
\hline 2 & Congestion condition & $\begin{array}{l}\text { 5: very mild; } 4 \text { : mild; } 3 \text { : neutral; } 2 \text { : serious; } 1 \text { : very } \\
\text { serious }\end{array}$ \\
\hline 3 & Income level & $\begin{array}{c}\text { 5: above } 8000 \text { yuan; } 4: 6000-8000 \text { yuan; } 3: \\
4000-6000 \text { yuan; } 2: 2000-4000 \text { yuan; } 1: \text { below } \\
2000 \text { yuan }\end{array}$ \\
\hline 4 & Years of use & $\begin{array}{c}2: 1-2 \text { years; } 4: 3-4 \text { years; } 6: 5-6 \text { years; } 8: 7-8 \text { years; } 10: \\
9-10 \text { years }\end{array}$ \\
\hline 5 & Deteriorating degree & $\begin{array}{c}0.5 \text { : very serious; } 0.4 \text { : serious; } 0.3 \text { : neutral; } 0.2 \text { : mild; } \\
0.1 \text { : very mild }\end{array}$ \\
\hline 6 & $\begin{array}{l}\text { Time cost coefficient (corresponding to the } \\
\text { psychological time) }\end{array}$ & $\begin{array}{c}\text { 1.5: very long; } 1.2 \text { : longer; } 1 \text { : neutral; } 0.8 \text { : short; } 0.5 \text { : } \\
\text { very short }\end{array}$ \\
\hline 7 & $\begin{array}{c}\text { Charging impedance coefficient (corresponding to } \\
\text { willingness to pay) }\end{array}$ & $\begin{array}{c}\text { 1.5: very low; } 1.2 \text { : lower; } 1 \text { : neutral; } 0.8 \text { : higher; } 0.5 \text { : } \\
\text { very high }\end{array}$ \\
\hline 8 & $\begin{array}{c}\text { Comfort coefficient (corresponding to the overall } \\
\text { comfort) }\end{array}$ & $\begin{array}{l}\text { 1.5: very comfortable; } 1.2 \text { : more comfortable; } 1 \text { : } \\
\text { neutral; } 0.8: \text { not too comfortable; } 0.5 \text { : very } \\
\text { uncomfortable }\end{array}$ \\
\hline
\end{tabular}

TABLE 5: Model summary.

\begin{tabular}{|c|c|c|c|c|}
\hline The dependent variable & $R$ & $R^{2}$ & Adjusted $R^{2}$ & The standard estimate error \\
\hline \multirow{2}{*}{ Time cost coefficient } & $0.937^{\mathrm{a}}$ & 0.877 & 0.870 & 0.0909 \\
\hline & \multicolumn{4}{|c|}{${ }^{a}$ Prediction variables: (constant), congestion condition, and road condition. } \\
\hline \multirow[b]{2}{*}{ Charging impedance coefficient } & $0.931^{\mathrm{a}}$ & 0.867 & 0.851 & 0.0946 \\
\hline & \multicolumn{4}{|c|}{$\begin{array}{c}{ }^{\mathrm{a}} \text { Prediction variables: (constant), road condition, congestion condition, income level, and } \\
\text { years of use }\end{array}$} \\
\hline \multirow{2}{*}{ Comfort coefficient } & $0.981^{\mathrm{a}}$ & 0.963 & 0.961 & 0.0493 \\
\hline & \multicolumn{4}{|c|}{${ }^{\text {a}}$ Prediction variables: (constant), congestion condition, and road condition. } \\
\hline
\end{tabular}

TABLE 6: Variance analysis.

\begin{tabular}{|c|c|c|c|c|c|c|}
\hline Model & & Sum of squares & $\mathrm{df}$ & Mean square & $F$ & Significance \\
\hline \multirow{4}{*}{ Time cost coefficient } & Regression & 2.006 & 2 & 1.003 & 121.489 & $0.000^{\mathrm{a}}$ \\
\hline & Residual & 0.281 & 34 & 0.008 & - & - \\
\hline & Totals & 2.287 & 36 & - & - & - \\
\hline & \multicolumn{6}{|c|}{${ }^{a}$ Prediction variables: (constant), congestion condition, and road condition. } \\
\hline \multirow{4}{*}{ Charging impedance coefficient } & Regression & 1.871 & 4 & 0.468 & 52.276 & $0.000^{\mathrm{a}}$ \\
\hline & Residual & 0.286 & 32 & 0.009 & - & - \\
\hline & Totals & 2.157 & 36 & - & - & - \\
\hline & \multicolumn{6}{|c|}{$\begin{array}{c}{ }^{a} \text { Prediction variables: (constant), road condition, congestion condition, income level, and years of } \\
\text { use }\end{array}$} \\
\hline \multirow{4}{*}{ Comfort coefficient } & Regression & 2.150 & 2 & 1.075 & 442.249 & $0.000^{\mathrm{a}}$ \\
\hline & Residual & 0.083 & 34 & 0.002 & - & - \\
\hline & Totals & 2.233 & 36 & - & - & - \\
\hline & \multicolumn{6}{|c|}{ a Prediction variables: (constant), congestion condition, and road condition. } \\
\hline
\end{tabular}


TABLE 7: Regression coefficient.

\begin{tabular}{|c|c|c|c|c|c|c|}
\hline \multirow[t]{2}{*}{ The dependent variable } & \multirow[t]{2}{*}{ The independent variables } & \multicolumn{2}{|c|}{$\begin{array}{l}\text { Unstandardized } \\
\text { coefficients }\end{array}$} & \multirow{2}{*}{$\begin{array}{c}\text { Standardized coefficients } \\
\text { Trial version }\end{array}$} & \multirow[t]{2}{*}{$t$} & \multirow[t]{2}{*}{ Siginificance } \\
\hline & & $B$ & Standard error & & & \\
\hline \multirow{3}{*}{ Time cost coefficient } & (Constant) & 2.059 & 0.068 & - & 30.356 & 0.000 \\
\hline & Road condition & -0.173 & 0.016 & -0.639 & -10.564 & 0.000 \\
\hline & Congestion condition & -0.169 & 0.013 & -0.759 & -12.560 & 0.000 \\
\hline \multirow{5}{*}{ Charging impedance coefficient } & (Constant) & 1.955 & 0.082 & - & 23.888 & 0.000 \\
\hline & Road condition & -0.109 & 0.020 & -0.413 & -5.322 & 0.000 \\
\hline & Congestion condition & -0.065 & 0.015 & -0.302 & -4.230 & 0.000 \\
\hline & Income level & -0.056 & 0.016 & -0.251 & -3.446 & 0.002 \\
\hline & Years of use & -0.049 & 0.010 & -0.430 & -5.031 & 0.000 \\
\hline \multirow{3}{*}{ Comfort coefficient } & (Constant) & -0.076 & 0.037 & - & -2.071 & 0.046 \\
\hline & Road condition & 0.171 & 0.009 & 0.636 & 19.154 & 0.000 \\
\hline & Congestion condition & 0.180 & 0.007 & 0.821 & 24.729 & 0.000 \\
\hline
\end{tabular}

scheme "returning loan by collecting tolls." It is similar with the PPP highway projects which need to charge users the tolls within a certain period to repay the loan. Therefore, they are selected for case study.

Jiangsu Expressway Company Limited is a listed company owning all or part of the rights and interests of the tolled bridges and highways in Jiangsu Province such as ShanghaiNanjing highway, Xicheng highway, and Guangzhou-Jingling highway. Its operation data can be accessed and can serve as the simulated data source. The rest traffic volume data of the highways are all from the local-related departments. Therefore, the simulated data source is reliable enough to establish the system dynamic model. After passing the reliability test, the model can be used to forecast the future traffic volume which can provide the scientific basis for adjusting the key contract conditions or other applications. The simulation took Node $\mathrm{A}$ as a starting point and Node $\mathrm{D}$ as a finishing point to simplify the simulation process. This paper only took the converted annual traffic between point $\mathrm{A}$ and $\mathrm{D}$ as the simulation basis. Because Nantong-Wuxi highway opened to traffic in 2010, this paper verifies the reliability of the traffic allocation model by fitting highway traffic from 2011 to 2016.

\subsection{System Dynamics Model of Traffic Allocation Rate of PPP} Highway. Based on formula (4), the relevant theories, and modeling of traffic allocation, three state variables were selected as the total traffic, $\mathrm{AB}$ section traffic, and $\mathrm{AC}$ section traffic. The corresponding rates were the traffic growth rates of each variables, respectively. The mean utility of sections could be calculated by formulas (2) and (3). Afterwards, traffic allocation rate and traffic volume will be determined according to the MNL model (formula (4)). The traffic volume of the specific year and previous year decided the traffic growth rate of sections. A complete feedback loop of traffic distribution was established. The stock and flow model of the PPP highway mean utility is shown in Figure 2.

\subsection{The Main Vensim Equations for the Road Mean Utility.} To simulate the traffic volume of a road, the quantitative relationship between variables which are called Vensim

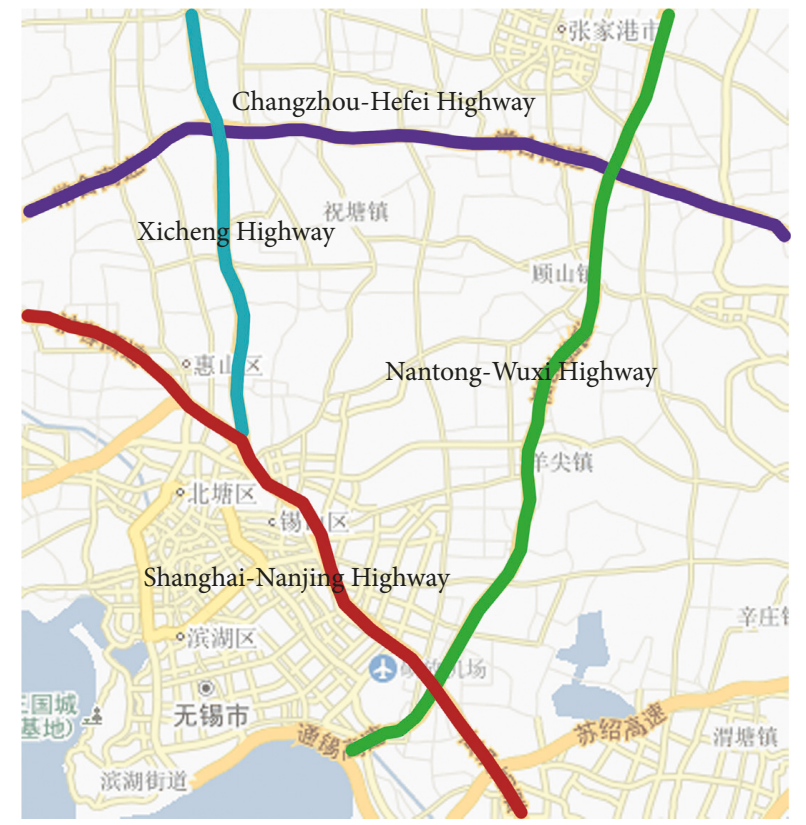

FIgURE 1: The sketch of network of the case highway.

equation and the related data from real projects should be input into the stock and flow model which we call normal system dynamic model of system dynamics (Figure 3) [30]. According to formula (3), the mean utility (Mi) in the system dynamics model is described as follows:

$M_{i}=$ time cost coefficient $a_{i 1} *$ section travel time SECTRTIME/comfort coefficient $\gamma_{i}+$ (charging impedance coefficient $a_{i 2} *$ section toll SECTOLL + fuel consumption coefficient $a_{i 3} *$ the petrol price of cars per a hundred kilometers CARPPRI) * section length SECLEG/the car time value CARTVLUE

This comprehensive mean utility function consists of two parts: travel time and tolls. Risk factors related to time, tolls, and comfort level were measured quantitatively to the timecost coefficient $a_{i 1}$, comfort coefficient $\gamma_{i}$, charging impedance coefficient $a_{i 2}$, etc. by using formula (5). Based on formula (4) and the highway conditions, the traffic allocation rate of the various highways of the calendar year could be 


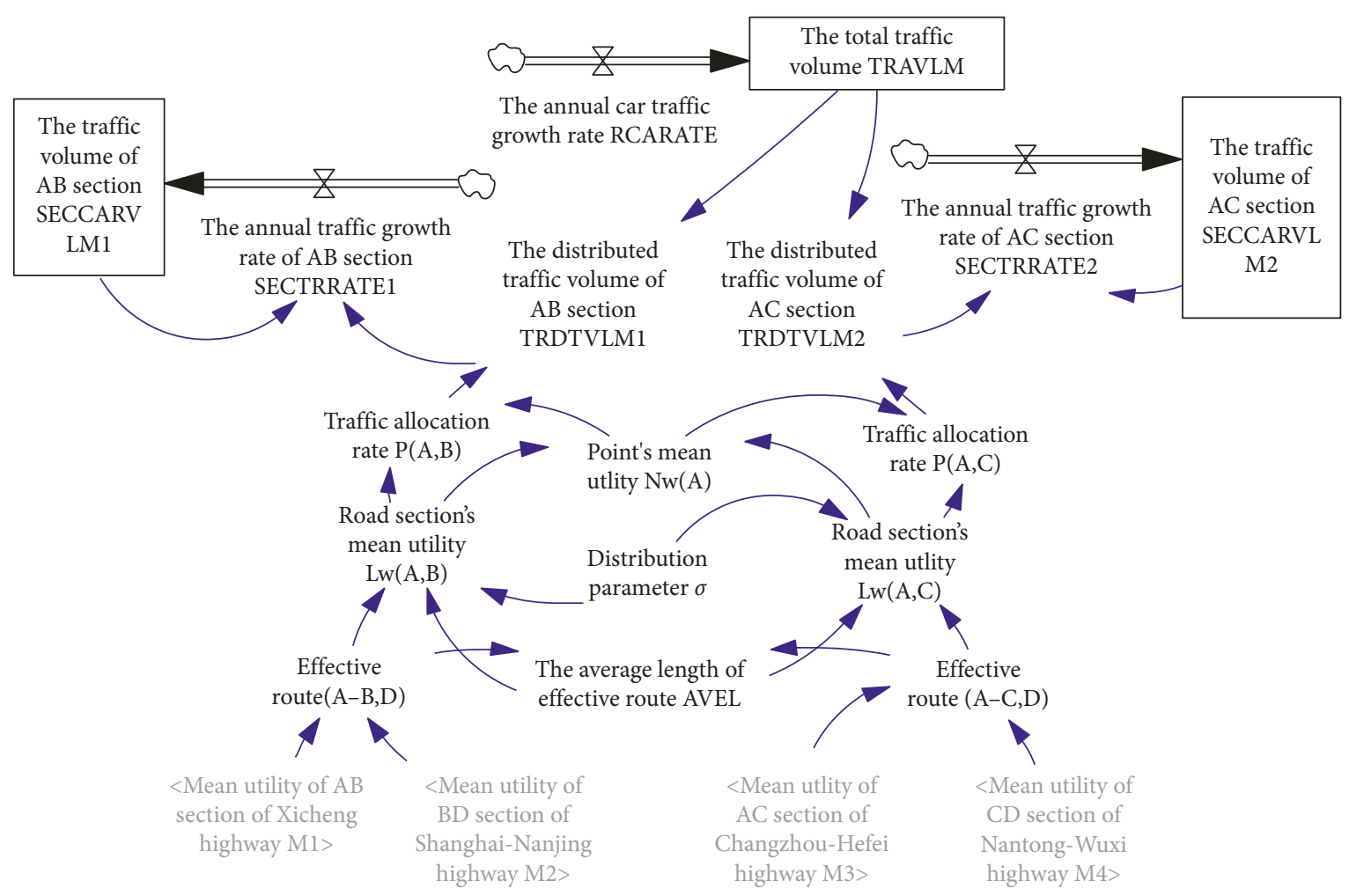

FIgURE 2: The stock and flow model of traffic allocation.

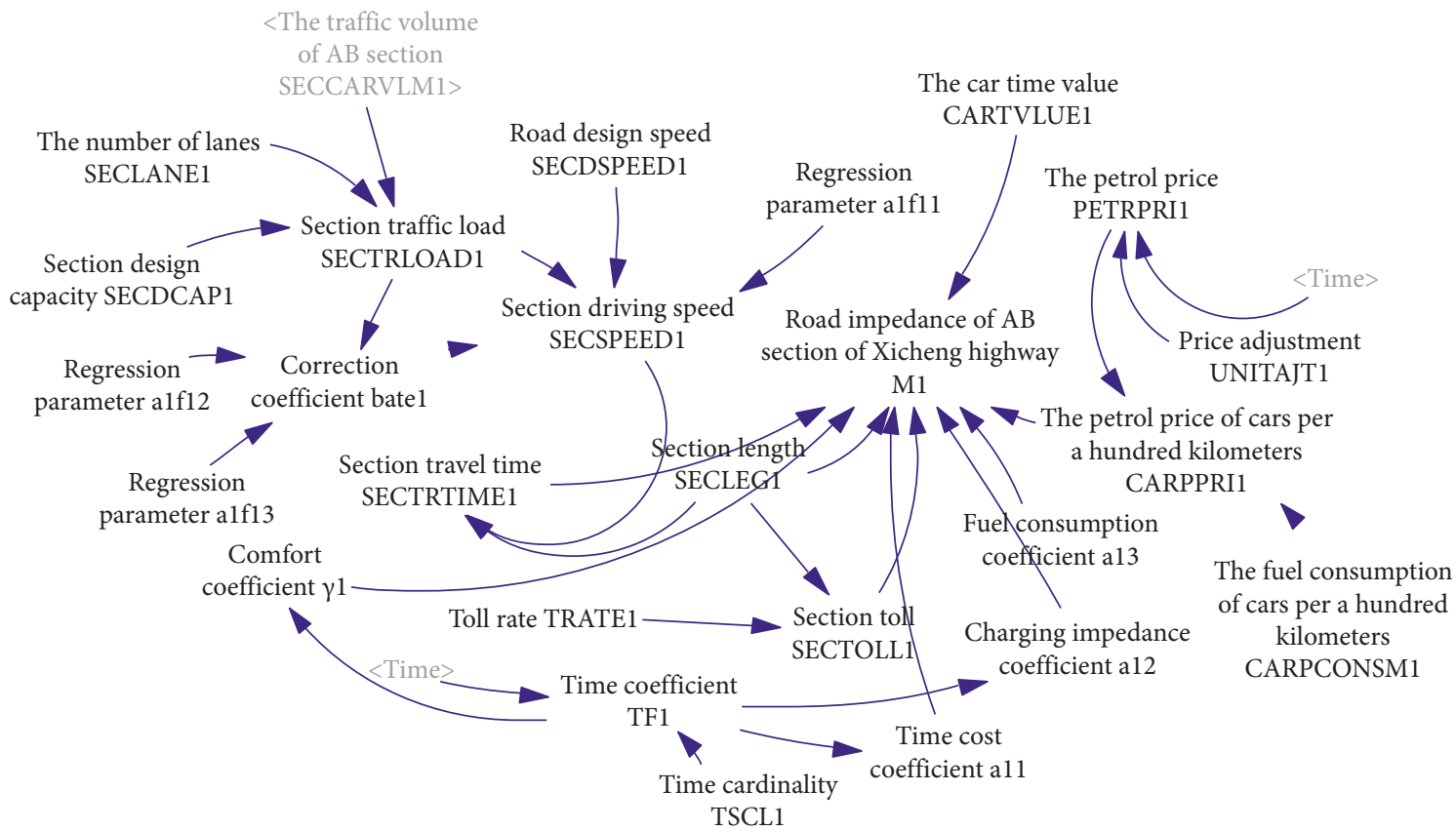

Figure 3: The normal system dynamic model of Xicheng highway.

computed by running the normal system dynamic model of Xicheng highway.

To determine the value of risk coefficients, a survey was conducted to determine the road condition and congestion level of the case roads, the survey shows the average deterioration value of current road conditions year-by-year was 0.21 , and the current congestion condition year-by-year was 0.3 . According to the operating conditions, NantongWuxi highway was opened to traffic in 2010. As a result, its initial value of road and congestion conditions was set as 5 . The initial value of road and congestion conditions of Changzhou-Hefei highway was set as 4 . Xicheng and 


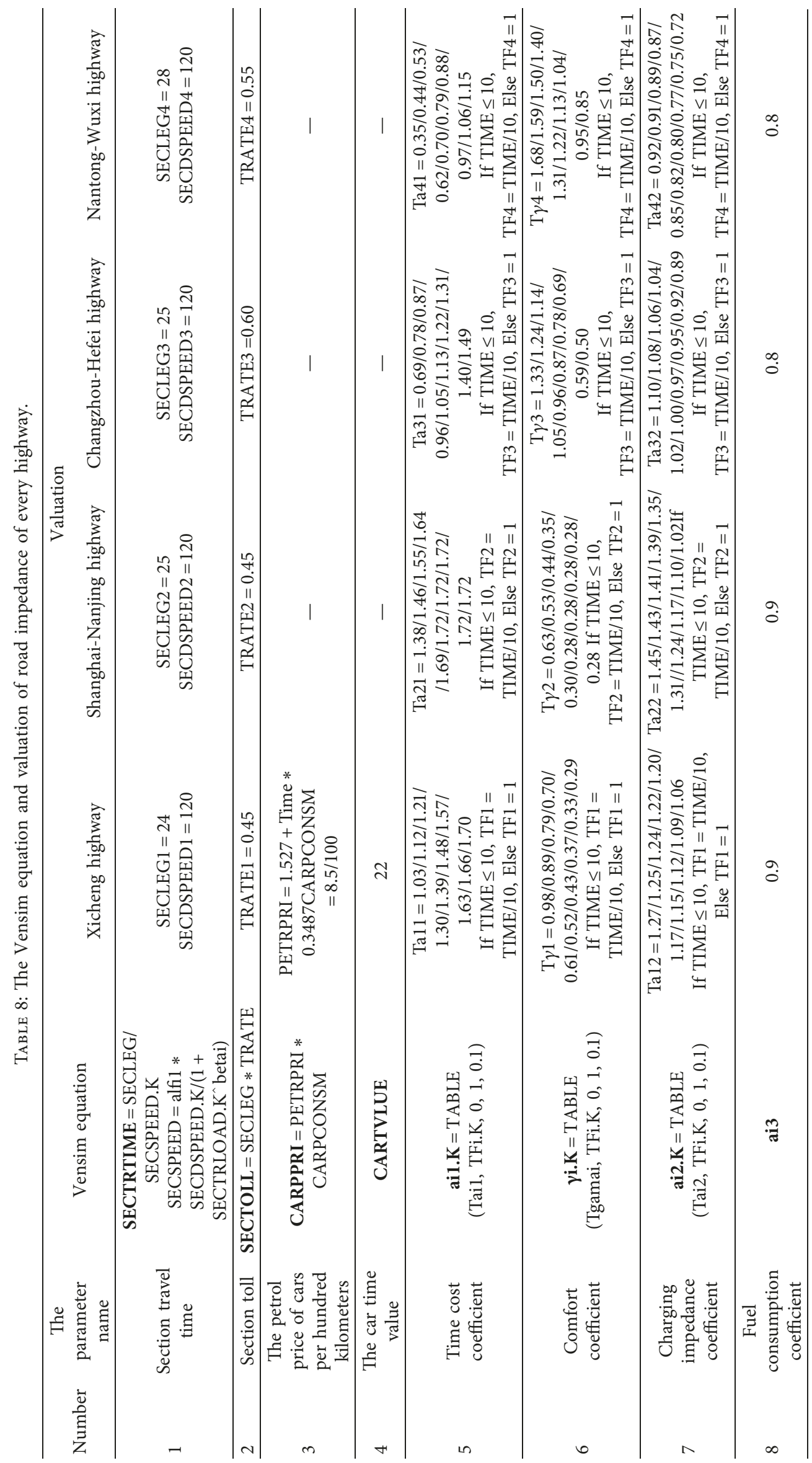


TABLE 9: The actual and simulated allocation of Xicheng expressway from 2011 to 2016.

\begin{tabular}{cccc}
\hline Year & $\begin{array}{c}\text { The actual traffic of Xicheng highway } \\
\text { (ten thousand vehicles/year) }(2)\end{array}$ & $\begin{array}{c}\text { The SD simulated traffic of Xicheng highway } \\
\text { (ten thousand vehicles/year) }(3)\end{array}$ & $\begin{array}{c}\text { The average error rate between SD simulated } \\
\text { traffic and actual traffic }((3)-(2)) /(2)\end{array}$ \\
\hline 2011 & 402.65 & 376.54 & $-6.49 \%$ \\
2012 & 435.81 & 410.07 & $-5.91 \%$ \\
2013 & 456.93 & 440.46 & $-3.60 \%$ \\
2014 & 478.67 & 470.91 & $-1.62 \%$ \\
2015 & 490.58 & 503.65 & $2.67 \%$ \\
2016 & 511.81 & 536.31 & $4.79 \%$ \\
& & \\
& The average error rate & $4.69 \%$ \\
\end{tabular}

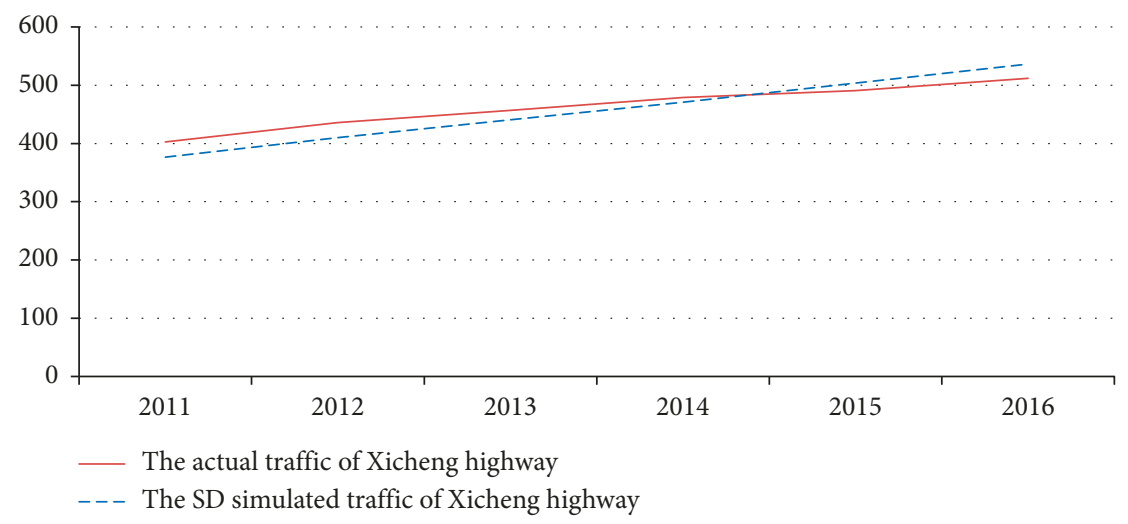

Figure 4: The comparison of the actual and simulated traffic volume of Xicheng Expressway.

Shanghai-Nanjing highway was opened to public earlier, and their traffic was higher. Shanghai-Nanjing highway was opened to public at the earliest date. Therefore, the initial value of road and congestion conditions of Xicheng highway was set as 3 . The initial value of road and congestion conditions of Shanghai-Nanjing highway was set as 2. In addition, the survey result showed that the average monthly income level of the private car owners was 3.24 (more than 6000 yuan). The average monthly income of the rest years could be pushed back according to per capita disposable income growth rate of $10.1 \%$ from National Bureau of Statistics of China. The values of main risk coefficients of each highway from 2011 to 2016 could be calculated based on formula (5). In addition, due to the heavy traffic of Xicheng and Shanghai-Nanjing highway, their driving distractions was bigger. Their fuel consumption of cars was slightly higher than the rest two highways. But because the highways are totally enclosed and the driving speed is uniform, their fuel consumption coefficient value was set as 0.9. The fuel consumption coefficient value of ChangzhouHefei and Nantong-Wuxi highway was set as 0.8 .

The values of the rest parameters of each highway were derived from the objective data. The Vensim equations of the parameters and the valuation are shown in Table 8.

5.4. Simulation Analysis of System Dynamics Specification Model of Xicheng Highway. The SD model of mean utility and traffic allocation model is used to simulate the traffic of Xicheng highway from 2011 to 2016 (Jiangsu Expressway
Company Limited) [31]. The simulation results are shown in Table 9 and Figure 4. The average error rate between actual traffic volume and SD simulated one of Xicheng highway is $1.69 \%$. The average absolute value of the error rate is $4.18 \%$. The error rate is very low. The model has accurately described the traffic volume changing trend of the case highway.

\section{Conclusions}

This paper studies the operation effectiveness of PPP highways. First, recent problematic PPP highway projects were deeply analyzed to identify the main risk factors related to traffic volume. Based on users' subjective feelings, risk coefficients were introduced to quantify relevant risks. The PPP highway traffic allocation model considering the effect of risks was established. The risk effects are statistically computed using multiple linear regression analysis via SPSS. One PPP highway project was simulated to validate the proposed traffic allocation model by comparing the actual traffic volume of the road with the simulated one. The simulation results show that the traffic allocation model can improve the accuracy of the traffic forecasting.

\section{Data Availability}

The data in the paper were received through the questionnaire survey, and the data in terms of the case were obtained from the website available publicly (http://www. jsexpressway.com/index.php? $\mathrm{m}=$ trafficflow\&c=index\&catid $=$ 113\&cid=126,152). 


\section{Conflicts of Interest}

The authors declare that they have no conflicts of interest.

\section{References}

[1] J. Li, "Dynamic contract conditions for built operation transfer (BOT) projects in China," International Journal of Construction Management, vol. 9, no. 2, pp. 55-64, 2009.

[2] Cngaosu, "The list of highway mileage of national provinces and cities (districts) in 2015," January 2016, http://news. cngaosu.com/dongtai/baogao/2016/01/50505.html.

[3] Government of prc., "The audit survey result of toll roads construction operation management situation of 18 provinces," Feburary 2008, http://www.gov.cn/zwgk/2008-02/27/ content_902834.htm.

[4] NetEase News, "The annual income from toll roads was four hundred billion but still suffered losses," October 2016, http:// data.163.com/16/1011/05/C32T27T6000181JR.html.

[5] Q. Shi, Y. Zhou, C. Xiao, R. Chen, and J. Zuo, "Delivery risk analysis within the context of program management using fuzzy logic and DEA: a China case study," International Journal of Project Management, vol. 32, no. 2, pp. 341-349, 2014.

[6] J. Zuo, R. Rameezdeen, M. Hagger, Z. Zhou, and Z. Ding, "Dust pollution control on construction sites: awareness and self-responsibility of managers," Journal of Cleaner Production, vol. 166, pp. 312-320, 2017.

[7] B. Ashuri, H. Kashani, K. R. Molenaar, S. Lee, and J. Lu, "Riskneutral pricing approach for evaluating bot highway projects with government minimum revenue guarantee options," Journal of Construction Engineering and Management, vol. 138, no. 4, pp. 545-557, 2012.

[8] K. C. Iyer and M. Sagheer, "A real options based traffic risk mitigation model for build-operate-transfer highway projects in India," Construction Management and Economics, vol. 29, no. 8, pp. 771-779, 2011.

[9] J. B. Song, L. L. Jin, and Y. N. Fu, "Adjustment decisions on toll and concession period for highway BOT project," Systems Engineering-Theory \& Practice, vol. 34, no. 8, pp. 2045-2053, 2014.

[10] D. Apronti, K. Ksaibati, K. Gerow, and J. J. Hepner, "Estimating traffic volume on Wyoming low volume roads using linear and logistic regression methods," Journal of Traffic and Transportation Engineering (English Edition), vol. 3, no. 6, pp. 493-506, 2016.

[11] H. K. Xiang, "Road impedance model study based on traffic wave theory," Journal of Shenzhen Polytechnic, vol. 15, no. 1, pp. 9-14, 2016.

[12] A. S. Soliñoa, A. L. L. Galeraa, and F. C. Colín, "Measuring uncertainty of traffic volume on motorway concessions: a time-series analysis," Transportation Research Procedia, vol. 27, pp. 3-10, 2017.

[13] B. W. Song, J. Y. Zhang, Q. Y. Li, and Q. Liu, "Improved dynamic road impedance function based on traffic wave theory," Journal of Chongqing Jiaotong University (Natural Sciences), vol. 33, no. 1, pp. 106-110, 2014.

[14] C. Q. Liu and J. Chen, "A deduction of impedance function based on Edie model and its fitting analysis," Communications Standardization, vol. 4, pp. 33-36, 2012.

[15] AS/NZS ISO31000, Risk Management: Principles and Guidelines, Standards Australia and Standards, New Zealand, 2009.
[16] S. Q. Wang, R. L. K. Tiong, S. K. Ting, and D. Ashley, "Evaluation and management of political risks in China's BOT projects," Journal of Construction Engineering and Management, vol. 126, no. 3, pp. 242-250, 2000.

[17] D. Kuchta, "Use of fuzzy numbers in project risk (criticality) assessment," International Journal of Project Management, vol. 19, no. 5, pp. 305-310, 2001.

[18] Y. Xu, J. F. Y. Yeung, A. P. C. Chan, D. W. M. Chan, S. Q. Wang, and Y. Ke, "Developing a risk assessment model for PPP projects in China-a fuzzy synthetic evaluation approach," Automation Construction, vol. 19, no. 7, pp. 929-943, 2010.

[19] J. Li and P. X. W. Zou, "Fuzzy AHP-based risk assessment methodology for PPP projects," Journal of Construction Engineering and Management, vol. 137, no. 12, pp. 1205-1209, 2011.

[20] Y. Ning and S. Q. Zhao, "Life-cycle risk identification based on AHP for rail transport PPP projects," Journal of Beijing University of Civil Engineering and Architecture, vol. 32, no. 2, pp. 28-32, 2014.

[21] Y. L. Wang, J. C. Liu, and J. Y. Lai, "Option game analysis based on risk preference in PPP projects," Journal of Engineering Management, vol. 27, no. 2, pp. 49-53, 2013.

[22] Y. Wu, L. W. Y. Li, R. H. Xu, K. F. Chen, Y. Hu, and X. S. Lin, "Risk assessment in straw-based power generation publicprivate partnership projects in China: a fuzzy synthetic evaluation analysis," Journal of Cleaner Production, vol. 161, pp. 977-990, 2017.

[23] C. Walker and A. J. Smith, Privatized Infrastructure: The Build Operate Transfer Approach, Thomas Telford, London, UK, 1995.

[24] A. Ng and M. Loosemore, "Risk allocation in the private provision of public infrastructure," International Journal of Project Management, vol. 25, no. 1, pp. 66-76, 2007.

[25] W. Wang and X. W. Chen, Transportation Planning, Communications Press, Beijing, China, 2007.

[26] D. McFadden and P. A. Talvitie, Demand Model Estimation and Validation, University of California, Berkeley, CA, USA, 1977.

[27] PCauto, "Real fuel consumption of 984 models," June 2009, http://drivers.pcauto.com.cn/yangche/fy/0906/860890.html.

[28] W. W. Fu, W. Z. Jin, and F. C. Lin, "Calculation of time value for urban public travel with MNL model," Journal of Transportation Systems Engineering and Information Technology, vol. 10, no. 2, pp. 148-152, 2010.

[29] S. C. Zhao, X. W. Wang, and Y. X. Zhang, "Value of drivers' commuting travel time," Journal of Transportation Systems Engineering and Information Technology, vol. 9, no. 1, pp. 109-112, 2009.

[30] Q. F. Wang, System Dynamics, Shanghai Finance and Economics University Press, Shanghai, China, 2009.

[31] Jiangsu Expressway Company Limited, "Traffic query during 2011-2016," 2016, http://www.jsexpressway.com/index.php? $\mathrm{m}=$ trafficflow $\& \mathrm{c}=$ index $\&$ catid $=113 \& \mathrm{cid}=126,152$. 


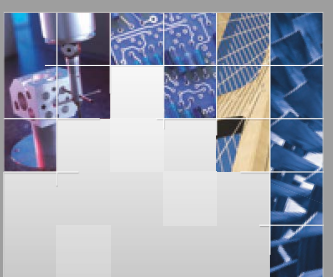

\section{Enfincering}
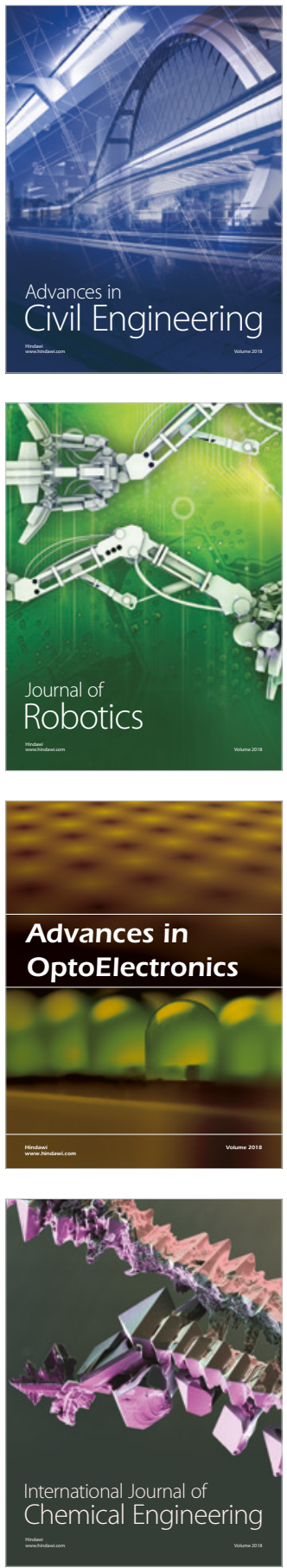

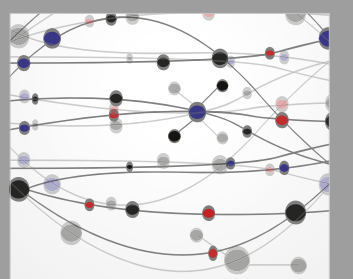

\section{Rotating \\ Machinery}

The Scientific World Journal

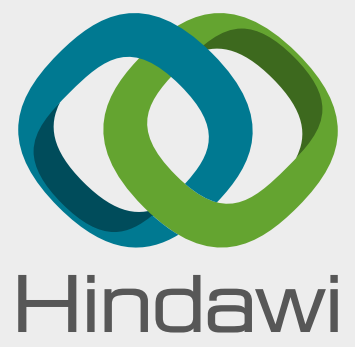

Submit your manuscripts at

www.hindawi.com
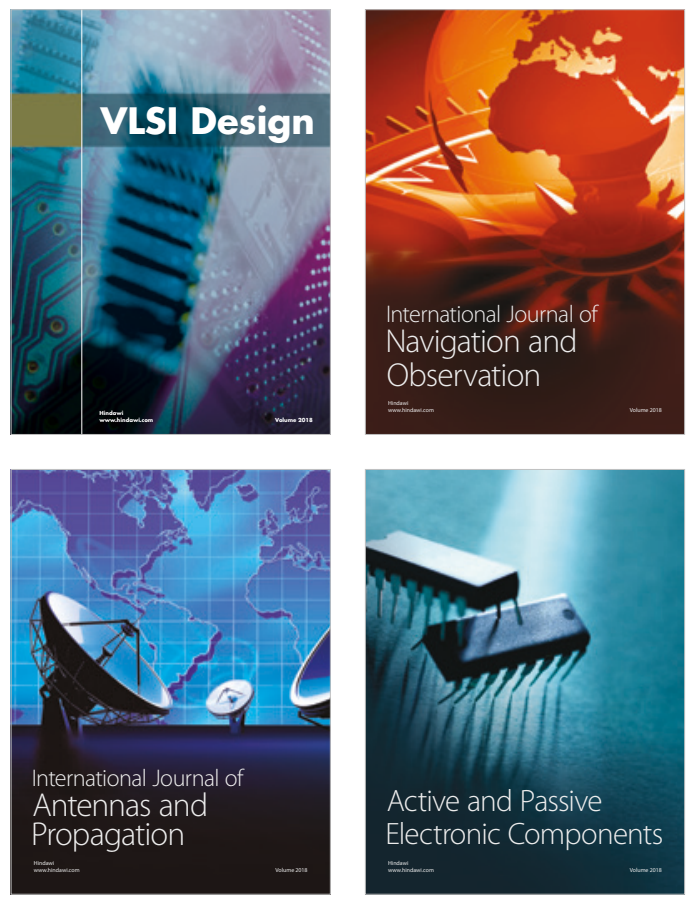
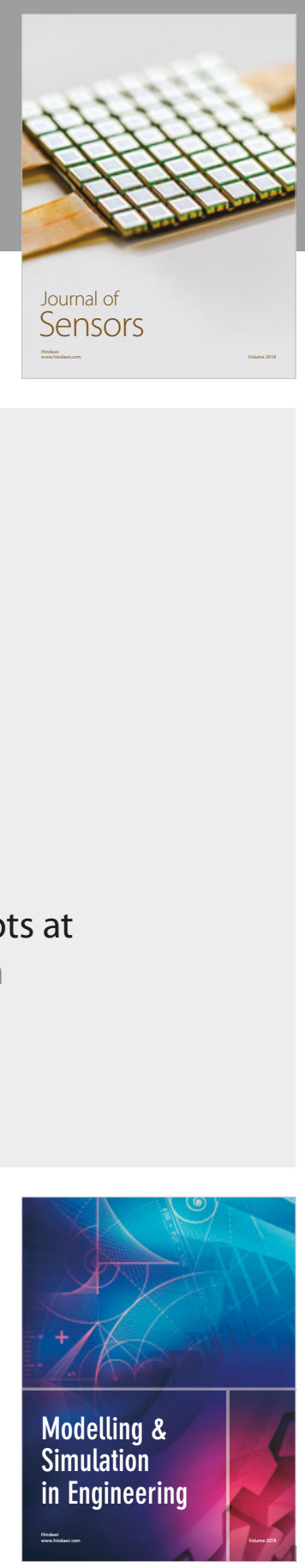

\section{Advances \\ Multimedia}
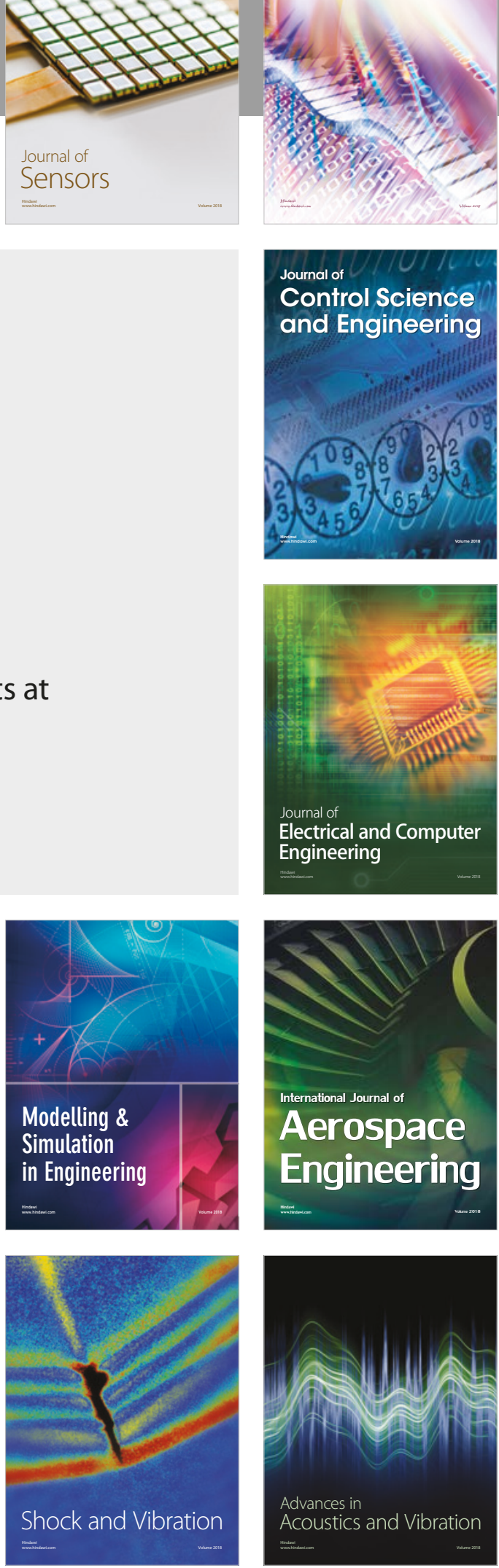